UDC 343.13

LBC 67.410 .2

\title{
THE PROBLEMS OF LEGAL ASSESSMENT OF FACTUAL CIRCUMSTANCES WHEN ADJUDICATING IN CRIMINAL PROCEEDINGS
}

\author{
Maksim V. Belyaev \\ Kazan Branch of Russian State University of Justice, Kazan, Russian Federation
}

\begin{abstract}
Introduction: the choice of the correct rule of law, based on a set of established circumstances of the case, determines the correctness of the court's decision. This selection occurs as a result of the implementation of logical mental activities, in which the court makes conclusions on the compliance of the established facts, the content of material or procedural norms. Methods: the methodological framework for this study is a set of methods of scientific knowledge, among which the main is the dialectical method, as well as the methods of systematicity, analysis and synthesis. Results: the author's standpoint grounded in the work is based on the legislation, judicial practice and opinions of the competent scientific community on the legal qualification of the factual circumstances of the case. Based on the analysis of the judicial practice, the levels of choice of legal norms to be applied are determined, and depending on the degree of definiteness of the legal norms, the models of the court's decision-making are distinguished. Conclusions: the choice of an appropriate legal rule for decision-making is carried out in two aspects: in terms of determining the full scope of the legal regulation and hierarchy of legal norms, subject to application, and in terms of the level of discretion of the court in choosing a legal rule. The selection of legal norms to be applied in terms of hierarchy means that the court should identify the content of the rule in the full legal regulation, not limited to the provisions of the Criminal Procedure Code of the Russian Federation, and to take into account the generally recognized norms and principles of international law, the provisions of the Constitution and its direct operation, as well as the precedents to the interpretation of law in the decisions of the Constitutional Court of the Russian Federation, the Resolutions of the Plenum of the Supreme Court and the ECHR. Depending on the level of discretion of the court in decision-making, due to the degree of definiteness of legal rules to be applied, it is necessary to distinguish three models of the court's decision-making: absolutely definite, relatively definite and alternative.
\end{abstract}

Key words: court's decision, legal assessment of factual circumstances of a case, interpretation of law, criminal procedure law, model of the court's decision.

Citation. Belyaev M.V. The Problems of Legal Assessment of Factual Circumstances When Adjudicaing in Criminal Proceedings. Legal Concept, 2018, vol. 17, no. 3, pp. 35-40. DOI: https://doi.org/10.15688/lc.jvolsu.2018.3.5

УДК 343.13

ББК 67.410 .2

\section{ПРОБЛЕМЫ ЮРИДИЧЕСКОЙ ОЦЕНКИ ФАКТИЧЕСКИХ ОБСТОЯТЕЛЬСТВ ДЕЛА ПРИ ПРИНЯТИИ СУДЕБНЫХ РЕШЕНИЙ В УГОЛОВНОМ СУДОПРОИЗВОДСТВЕ}

\footnotetext{
Максим Владимирович Беляев

Казанский филиал Российского государственного университета правосудия, г. Казань, Российская Федерация

Введение: выбор правильной нормы права, основанный на совокупности установленных обстоятельств дела, предопределяет правильность выносимого судом решения. Этот выбор происходит в результате осуществления мыслительной логической деятельности, в ходе которой суд делает умозаключения о соответствии установленных фактов содержанию материальных или процессуальных норм. Методы: методологическую основу данного исследования составляет совокупность методов научного познания, среди которых основное место занимают диалектический метод, а также методы системности, анализа и синтеза. Результаты: обосно-
} 
ванная в работе авторская позиция опирается на законодательство, судебную практику и мнения компетентной научной среды по вопросу о юридической квалификации фактических обстоятельств дела. На основании анализа судебной практики определяются уровни выбора подлежащих применению правовых норм, в зависимости от степени определенности правовых норм выделяются модели принятия судебных решений. Выводы: выбор надлежащей правовой нормы для принятия решения осуществляется в двух плоскостях: с позиций определения полного объема правового регулирования и иерархичности правовых норм, подлежащих применению, а также с позиций уровня дискреционности полномочий суда при выборе правовой нормы. Выбор правовой нормы, подлежащей применению, с позицией иерархичности означает, что суд должен выявить содержание нормы в полном объеме правового регулирования, не ограничиваясь положениями УПК РФ, а принимать во внимание общепризнанные нормы и принципы международного права, положения Конституции РФ и пределы ее прямого действия, а также прецеденты толкования норм права, находящиеся в решениях Конституционного Суда РФ, Постановлениях Пленума Верховного Суда РФ и ЕСПЧ. В зависимости от уровня дискреционности полномочий суда при принятии решений, обусловленной степенью определенности правовых норм, подлежащих применению, необходимо выделить три модели принятия судебных решений: абсолютно определенную, относительно определенную и альтернативную.

Ключевые слова: судебное решение, юридическая оценка фактических обстоятельств дела, толкование норм права, уголовно-процессуальный закон, модель принятия судебного решения.

Цитирование. Беляев М. В. Проблемы юридической оценки фактических обстоятельств дела при принятии судебных решений в уголовном судопроизводстве // Legal Concept = Правовая парадигма. - 2018. T. 17, № 3. - C. 35-40. - DOI: https://doi.org/10.15688/lc.jvolsu.2018.3.5

\section{Введение}

Важнейшим этапом принятия судебного решения выступает этап правовой квалификации установленных ранее фактических обстоятельств дела, в ходе которого им дается юридическая оценка.

Содержанием этого этапа является выбор юридической нормы, подлежащей применению, ее анализ и толкование. Нельзя не согласиться с Л.А. Воскобитовой в вопросе о том, что данный этап можно условно разделить на два этапа - отыскание адекватной правовой нормы и проверка ее юридической силы, толкование и уяснение ее подлинного смысла; при этом в практике правоприменения эти этапы разделить весьма затруднительно (цит. по: [3, с. 87]).

Выбор правильной нормы права, основанный на совокупности установленных обстоятельств дела, предопределяет и правильность выносимого судом решения. Если установление фактических обстоятельств дела осуществляется посредством доказывания, то выбор нормы права, подлежащей применению, происходит в результате осуществления мыслительной логической деятельности, в ходе которой суд делает умозаключения о соответствии установленных фактов содержанию материальных или процессуальных норм.

\section{Уровни выбора правовой нормы при принятии решения}

Анализ судебной практики приводит к выводу о необходимости понимания проблем выбора надлежащей правовой нормы для принятия решения с двух позиций: уровня иерархичности правовых норм, подлежащих применению, а также степени усмотрения суда при выборе правовой нормы.

Выбор правовой нормы, подлежащей применению, с позицией иерархичности означает, что суд должен выявить содержание нормы в полном объеме правового регулирования, не ограничиваясь положениями УПК РФ.

Трудно не согласиться с Л.А. Воскобитовой, которая пишет о том, что уяснение смысла правовой нормы сопряжено с необходимостью учитывать не только текст УПК РФ, но и понимать пределы прямого действия норм Конституции РФ; принимать во внимание решения Конституционного Суда РФ, дающего толкование норм УПК РФ в их системном и конституционно-правовом смысле; учитывать решения ЕСПЧ, основанные на толковании норм Европейской Конвенции; разъяснения Пленума Верховного Суда РФ, а также его практику. Причем все эти положения необходимо применять не альтернативно, а в их системном единстве (цит. по: [3, с. 88]). В ряде случаев толкование правовых норм, подлежащих применению в 
деле, осуществляется Конституционным Судом РФ, Верховным Судом РФ, ЕСПЧ. В случае, если толкования правовых норм, данных Конституционным Судом РФ, Верховным Судом РФ, недостаточно для уяснения смысла конкретной правовой нормы либо такое толкование отсутствует, суд осуществляет толкование применяемых норм самостоятельно, с учетом конкретных фактических обстоятельств уголовного дела.

Пример тому - рассмотрение уголовных дел, расследованных в форме сокращенного дознания. Противоречие между положениями ч. 1 и ч. 2 ст. 226.9. УПК РФ (согласно ч. 1 рассмотрение уголовного дела осуществляется в особом порядке без исследования фактических обстоятельств дела; в соответствии с ч. 2 приговор постановляется на основании исследования и оценки только тех доказательств, которые указаны в обвинительном постановлении, а также дополнительных данных о личности подсудимого) привело к различному толкованию судами данной нормы. Результатом этого стала различная судебная практика: в ряде регионов суды рассматривают такие уголовные дела в особом порядке, в других регионах - в общем порядке.

Важно понимать, что толкование норм права не является правотворчеством, в результате его осуществления не создаются новые нормы и правила поведения. В этом смысле следует согласиться с В.О. Белоносовым, настаивающим на том, что при толковании норм уголовнопроцессуального права достигается более конкретизированное и детализированное знание о содержании общей и абстрактной нормы, происходит ее приближение к конкретным условиям правоприменения, однако при этом не может быть ничего, что не было предусмотрено в абстрактной формулировке нормативного предписания $[1$, c. 10]. А.С. Пиголкин писал о том, что в процессе толкования правовая норма сама по себе остается неизменной с точки зрения содержания, и задача толкования ограничивается лишь установлением того смысла, который вложил в нее законодатель [4, с. 20].

\section{Модели принятия судебных решений}

С позиций степени усмотрения суда при выборе правовых норм следует обратиться к традиционно выделяемым в науке уголовнопроцессуального права моделям принятия решений в зависимости от вида нормативных предписаний, применяемых при принятии решения. П.А. Лупинская выделяет модели принятия судебных решений, основываясь на дифференциации процессуальных норм на абсолютно определенные и относительно определенные [2, с. 48-55]. Соглашаясь с такой позицией в целом, следует отметить целесообразность выделения еще одной правовой модели принятия судебного решения - модели, основанной на альтернативных уголовно-процессуальных нормах права, предоставляющих возможность выбора одного из нескольких вариантов возможного поведения при одних и тех же фактических обстоятельствах дела. Таким образом, модели принятия судебных решений могут быть определены в зависимости от степени определенности применяемых норм: абсолютно определенных, относительно определенных, предполагающих определенную возможность выбора, и альтернативных, предоставляющих несколько вариантов возможного поведения.

Большинство процессуальных норм носят императивный характер и не предполагают возможности выбора вариантов поведения. Способ действия суда четко определен содержанием нормы. В этом случае правильность принимаемого решения целиком зависит от того, насколько верно установлены фактические обстоятельства дела.

Так, получив уведомление о проведенных в исключительных случаях без судебного решения следственных действиях, суд проверяет их законность в соответствии с ч. 5 ст. 165 УПК РФ. В случае, если данное следственное действие безосновательно было проведено без решения суда либо был нарушен порядок его проведения, суд не может вынести другого решения, кроме как признать его незаконным.

Например, по делу Л. следователем было вынесено постановление о производстве обыска в случаях, не терпящих отлагательств. Обосновано оно было просто фразой «наличие обстоятельств, не терпящих отлагательств», но каких именно, не раскрыто. Суду также не было представлено конкретных доводов, указывающих на необходимость незамедлительного производства обыска. В ито- 
ге Набережночелнинский городской суд признал обыск незаконным ${ }^{1}$.

Вторая модель принятия судебного решения основывается на нормах с относительно определенной гипотезой и диспозицией. В этой ситуации, как верно писала П.А. Лупинская, «гипотеза нормы дает возможность... учесть обстоятельства конкретного дела, которые не типизированы в законе путем перечня конкретных признаков, имеющих строго определенное правовое значение, а даны в форме общей характеристики юридических фактов. При этом правоприменительный орган решает, имеются ли в конкретных обстоятельствах дела те признаки, свойства, которые в общем виде сформулированы в гипотезе нормы» [2, с. 53].

Как правило, в УПК РФ такие нормы содержат формулировки «вправе», «может», «в случае необходимости» и т. п., которые предполагают усмотрение суда при принятии данного решения. Принимая решение на основе относительно определенной нормы права, суд на основе конкретных фактических обстоятельств дела выбирает возможный вариант поведения. При этом дискреционные полномочия суда ограничены оценкой фактических обстоятельств дела. Непременным условием принятия такого решения является умозаключение суда о том, что данный конкретный случай содержит признаки, в общем виде сформулированные в правовой норме. Это умозаключение носит оценочный характер, поскольку от того, как суд оценит фактические обстоятельства, зависит, определит ли он в них наличие тех признаков, с которыми связывается возможность принятия данного решения. При наличии признаков, в совокупности составляющих основания для принятия такого решения, право суда трансформируется в обязанность его вынести.

К числу таких решений относятся, в первую очередь, решения о прекращении уголовного преследования при наличии к тому небезусловных оснований - ввиду деятельного раскаяния, с применением судебного штрафа и т. д. Если суд принимает решение об отказе в удовлетворении ходатайства об отказе в прекращении уголовного преследования, он должен обосновать свое решение фактическими обстоятельствами дела и мотивировать его. Так, Верховный Суд Республики Татарстан отменил обвинительный приговор, вынесенный Нижнекамским городским судом в отношении Ш., осужденной за применение насилия, неопасного для жизни и здоровья, в отношении инспектора ГИБДД, и прекратил уголовное дело с применением судебного штрафа. Прекращая дело, апелляция учла, что Ш. ранее не судима, признала вину, загладила причиненный потерпевшему вред, преступление законом отнесено к категории средней тяжести, то есть препятствий к прекращению уголовного дела и вынесению решения о применении судебного штрафа не имелось ${ }^{2}$.

Третья модель принятия судебного решения основывается на альтернативных нормах права и предполагает возможность выбора одного из нескольких возможных вариантов при одних и тех же фактических обстоятельствах дела. Эта модель принятия судебного решения может применяться при выборе мер пресечения, видов и размера наказания в обвинительном приговоре суда и т. д.

Особой разновидностью альтернативной модели принятия судебного решения является модель, при которой применяемая норма права не указывает на конкретные варианты поведения, а предоставляет суду возможность выбрать их по своему усмотрению. Так, например, суд с учетом позиции сторон принимает решение о порядке исследования доказательств при рассмотрении уголовного дела по существу, а суд апелляционной инстанции определяет, какие доказательства могут быть исследованы в ходе судебного заседания.

Избираемый вариант решения должен отвечать тем целям, для достижения которых решение избирается. Так, разрешая вопрос об условно-досрочном освобождении осужденного от дальнейшего отбывания наказания, суд, основываясь на данных о личности осужденного, не только делает умозаключение вероятностного характера о том, что фактические данные свидетельствуют о том, что для достижения целей наказания осужденный не нуждается в дальнейшем его отбывании, но и прогнозирует, какое воздействие вынесенное решение может оказать на будущее поведение данного лица. Совокупное прогнозирование судами индивидуального поведения осужденных, освобожденных из мест отбывания 
наказания условно-досрочно, имеет далеко идущие последствия, затрагивающие не только участников уголовно-правового конфликта, в том числе динамику рецидивной преступности, социальную обстановку в регионе и т. д. Трудности принятия подобного рода решений заключаются в неправильной оценке обстоятельств дела, ведущей к неправильному решению. Так, Приволжским районным судом А., осужденный за мошенничество в особо крупном размере, освобожден условно-досрочно. Он имел 10 взысканий, причем последнее наложено в 2017 г. и 2 поощрения, которые получены незадолго до обращения в суд с ходатайством об УДО. Администрация и прокуратура не поддержали ходатайство, однако суд принял другое решение. Мошенник А. с иском почти в 2 миллиарда рублей освобожден на 1 год и 3 месяца раньше. По другому делу Нижнекамский городской суд И., осужденному за кражу, отказывает в удовлетворении УДО на 3 месяца, а И. имеет 8 пошрений, ноль взысканий, трудоустроен и принимает активное участие в общественной жизни. Примечательно, что ходатайство поддержал не только представитель администрации, но и прокурор, что бывает крайне редко. Против оказался только судья, но законный мотив привести не смог ${ }^{3}$. Очевидно, в данных случаях суды приняли неправильные решения.

\section{Выводы}

Выбор надлежащей правовой нормы для принятия решения осуществляется в двух плоскостях: с позиций определения полного объема правового регулирования и иерархичности правовых норм, подлежащих применению, а также с позиций уровня дискреционности полномочий суда при выборе правовой нормы. Выбор правовой нормы, подлежащей применению, с позицией иерархичности означает, что суд должен выявить содержание нормы в полном объеме правового регулирования, не ограничиваясь положениями УПК РФ, а принимая во внимание общепризнанные нормы и принципы международного права, положения Конституции РФ и пределы ее прямого действия, а также прецеденты толкования норм права, находящиеся в решениях Конституционного Суда РФ, Постановлениях Пле- нума Верховного Суда РФ и ЕСПЧ. В зависимости от уровня дискреционности полномочий суда при принятии решений, обусловленной степенью определенности правовых норм, подлежащих применению, необходимо выделить три модели принятия судебных решений: абсолютно определенную, относительно определенную и альтернативную.

\section{ПРИМЕЧАНИЯ}

1 Архив Набережночелнинского городского суда за 2017 г.

2 Архив Верховного Суда Республики Татарстан за 2017 г.

3 Там же.

\section{СПИСОК ЛИТЕРАТУРЫ}

1. Белоносов, В. О. Толкование норм права в системе теоретической и практической деятельности в сфере уголовного судопроизводства : автореф. дис. ... д-ра юрид. наук / Белоносов Владимир Олегович. - Саратов, 2009. - 41 с.

2. Лупинская, П. А. Решения в уголовном судопроизводстве : Их виды, содержание и формы / П. А. Лупинская. - М. : Юрид. лит., 1976. - 168 с.

3. Масленникова, Л. Н. Доказывание и принятие решений в уголовном судопроизводстве / Л. Н. Масленникова. - М. : Норма : Инфра-М, 2017.-384 с.

4. Пиголкин, А. С. Толкование нормативных актов в СССР / А. С. Пиголкин. - М. : Юстицинформ, 2005. - 144 c.

\section{REFERENCES}

1. Belonosov V.O. Tolkovanie norm prava v sisteme teoreticheskoy $i$ prakticheskoy deyatelnosti $v$ sfere ugolovnogo sudoproizvodstva: avtoref. diss. ... d-ra yurid. nauk [Interpretation of Legal Norms in the System of Theoretical and Practical Activities in the Sphere ofCriminal Justice. Dr. jurid. sci. abs. diss.]. Saratov, 2009. 41 p.

2. Lupinskaya P.A. Resheniya v ugolovnom sudoproizvodstve: ikh vidy, soderzhanie $i$ formy [Decisions in Criminal Proceedings: Types, Content and Forms]. Moscow, Yurid. lit. Publ., 1976. 168 p.

3. Maslennikova L.N. Dokazyvanie i prinyatie resheniy v ugolovnom sudoproizvodstve [Proving and Making Decisions in Criminal Proceedings]. Moscow, Norma; Infra-M Publ., 2017.384 p.

4. Pigolkin A.S. Tolkovanie normativnykh aktov $v$ SSSR [Interpretation of Regulatory Acts in the USSR]. Moscow, Yustitsinform Publ., 2005. 144 p. 


\section{Information about the Author}

Maksim V. Belyaev, Candidate of Sciences (Jurisprudence), Deputy Chairman of the Supreme Court of the Republic of Tatarstan, Professor of the Department of Criminal Law, Kazan Branch of Russian State University of Justice, Pushkina St., 72/2, 420015 Kazan, Russian Federation, 2216406@mail.ru.

\section{Информация об авторе}

Максим Владимирович Беляев, кандидат юридических наук, заместитель Председателя Верховного Суда Республики Татарстан, профессор кафедры уголовного права, Казанский филиал Российского государственного университета правосудия, ул. Пушкина, 72/2, 420015 г. Казань, Российская Федерация, 2216406@mail.ru. 